\title{
Temas ambientais como "temas geradores": contribuições para uma metodologia educativa ambiental crítica, transformadora e emancipatória
}

\section{Environmental issues as generating issues: contributions to a critical, transforming and emancipating environmental educating methodology}

\author{
Marília Freitas de Campos Tozoni-Reis* \\ "sequir-me é não me seguir; é reinventar-me" \\ Paulo Freire
}

\section{RESUMO}

\begin{abstract}
A educação ambiental crítica e emancipatória exige que os conhecimentos sejam apropriados, construídos, de forma dinâmica, coletiva, cooperativa, contínua, interdisciplinar, democrática e participativa, voltados para a construção de sociedades sustentáveis. Este artigo trata dos temas ambientais como temas geradores para a educação ambiental, inspirados na pedagogia Paulo Freire, para quem educar é um ato de conhecimento da realidade concreta, das situações vividas, um processo de aproximação crítica da própria realidade: compreender, refletir, criticar e agir são as ações pedagógicas pretendidas. Os temas geradores são, portanto, estratégias metodológicas de um processo de conscientização da realidade opressora vivida nas sociedades desiguais; são o ponto de partida para o processo de construção da descoberta, e, por emergir do saber popular, os temas geradores são extraídos da prática de vida dos educandos, substituindo
\end{abstract}

* Doutora em Educação pela Unicamp. Professora da Universidade Estadual Paulista - Unesp. E-mail: mariliaedu@ibb.unesp.br 
TOZONI-REIS, M. F. de C. Temas ambientais como "temas geradores"...

os conteúdos tradicionais e buscados através da pesquisa do universo dos educandos. O caráter político da pedagogia freireana faz-se presente, de forma radical, nos temas geradores, isto é, temas geradores só são geradores de ação-reflexão-ação se forem carregados de conteúdos sociais e políticos com significado concreto para a vida dos educandos. Assim, as propostas educativas ambientais conscientizadoras podem tomar os temas ambientais locais como temas geradores desta ação conscientizadora, desde que estes temas contenham conteúdos socioambientais significativos para os educandos e sejam definidos coletiva e participativamente.

Palavras-chave: temas ambientais; temas geradores; metodologia da educação ambiental; conscientização.

\section{ABSTRACT}

The emancipating and critical environmental education demands that knowledge must be adequate, build up in a dynamic, collective, cooperating, continuous, interdisciplinary, democratic and participating way directed to the construction of self-maintaining societies. This paper deals with environmental issues as generating issues for an environmental education inspired in Paulo Freire's pedagogy. According to him to educate is to know the reality in its experienced situations, as an ongoing critical process of closeness to the reality itself: to understand, to ponder, to criticize and to act are the intended pedagogical attitudes. The generating issues are strategic methods of a process of awareness about an oppressive reality in unequal societies. Such issues are the starting point to the process of building up a discovery. The generating issues spring out of the popular knowledge, taken from the daily life of the educating ones in order to replace the traditional contents. The political aspect of Paulo Freire's pedagogy are to be seen in the generating issues insofar as these ones contemplate the social and political contents that are meaningful to the life of the educating people. In this way all the educating proposals should take into consideration the local environmental issues as generating issues to the desired consciousness. Finally, it is important to say that the educating people should take part in defining and determining the issues that represent their interests as the content for an environmental and social action.

Key-words: environmental issues; generating issues; environmental education methodology; awareness. 


\section{Introdução}

Para compreender o estágio atual de desenvolvimento da educação ambiental é necessário identificar alguns marcos históricos importantes na preocupação do homem com o ambiente, muito presente, hoje, em toda a sociedade, apesar de todas as suas contradições. Essa preocupação faz parte da história da humanidade. Encontramos nos registros do pensamento de artistas, filósofos e cientistas desde a Antigüidade, reflexões acerca da relação dos homens com a natureza, seja pelas reflexões filosóficas acerca da natureza humana, seja pela expressão de admiração com a natureza presentes nesses registros. Mas, foi no século XX que essa preocupação tomou vulto em conseqüência das transformações da forma de organizar a produção e a reprodução da vida definidas pela Revolução Industrial no final do século XVIII. Esse novo modelo de produção articulado com a nova ciência, a ciência moderna, promoveu o desenvolvimento econômico e científico num ritmo espantosamente acelerado. A humanidade entrou na modernidade com uma nova estruturação do poder científico, político e social, e, conseqüentemente, com novos problemas. Podemos dizer que a preocupação com o ambiente se acentuou quando a humanidade se viu ameaçada pelo poder de destruição total do ambiente que tem como marco histórico a bomba atômica sobre Hyroshima e Nagazaki no final da Segunda Guerra Mundial, em 1945 - expressão do poder político e econômico de um país sobre o mundo social e natural. Nesse momento os homens expressaram a conquista do poder de destruição total da vida sobre o planeta. Podemos dizer que foi neste momento que o movimento ambientalista teve origem.

Desde então, muito se tem discutido sobre a educação ambiental e suas formas de realização. Nos vários e diferentes eventos nacionais e internacionais, espaços importantes para a construção de diretrizes filosófico-políticas para a educação ambiental, a busca da sustentabilidade foi apontada como a principal tarefa da educação ambiental.

O Tratado da Educação Ambiental para Sociedades Sustentáveis e Responsabilidade Global, um dos principais documentos de referência da educação ambiental pactuado no Fórum das ONGs que aconteceu no Rio de Janeiro em junho de 1992, paralelamente à Conferencia das Nações Unidas para o Meio Ambiente, a Eco92, reconhece a educação como direito dos cidadãos e firma posição na educação transformadora. Esse documento, principal referência para muitos educadores ambientais, merece destaque por se tratar de posições não-governamentais, isto é, posições da sociedade civil organizada em entidades ambientalistas. O Trata- 
TOZONI-REIS, M. F. de C. Temas ambientais como “temas geradores”...

do convoca as populações a assumirem suas responsabilidades, individual e coletivamente, para cuidar do ambiente:

\begin{abstract}
... a educação ambiental para uma sustentabilidade eqüitativa é um processo de aprendizagem permanente, baseado no respeito a todas as formas de vida. Tal educação afirma valores e ações que contribuem para a transformação humana e social e para a preservação ecológica. Ela estimula a formação de sociedades socialmente justas e ecologicamente equilibradas, que conservem entre si a relação de interdependência e diversidade. Isto requer responsabilidades individual e coletiva no nível local, nacional e planetário. (Fórum Internacional das ONGs, 1995)
\end{abstract}

Desde então, a educação ambiental para a sustentabilidade é considerada um processo de aprendizagem permanente, baseado no respeito a todas as formas de vida e que afirma valores e ações que contribuam para as transformações socioambientais exigindo responsabilidades individual e coletiva, local e planetária. A sustentabilidade é entendida como fundamento da educação ambiental crítica, transformadora e emancipatória, compreendida como estratégia para a construção de sociedades sustentáveis, socialmente justas e ecologicamente equilibradas. A educação ambiental para a sustentabilidade é, assim, uma educação política, democrática, libertadora e transformadora. A questão ambiental e a educação, sem perspectiva de neutralidade, são eminentemente políticas, portanto, implicam em construir, pela participação radical dos sujeitos envolvidos, as qualidades e capacidades necessárias à ação transformadora responsável diante do ambiente em que vivemos.

No entanto, a educação ambiental crítica e transformadora não é consenso entre aqueles que vêm se dedicando a realizá-la. Trata-se de uma escolha político-educativa marcada pela idéia de que vivemos numa sociedade ecologicamente desequilibrada e socialmente desigual, resultado das escolhas históricas que fizemos para nos relacionarmos com o ambiente. No entanto, o amadurecimento da educação ambiental como campo de pesquisa e ação educativa tem permitido superar a tendência de tratá-la como disciplina ou programa vinculado ao ensino de ciências, biologia ou áreas afins, para inseri-la num contexto mais amplo, como educação. Neste sentido, buscamos conferir à educação um caráter ambiental, inserir na educação, crítica e transformadora, o tema ambiental: educação ambiental é, então, a educação que tematiza o ambiente. 
Educação Ambiental é dimensão da educação, é atividade intencional da prática social, que imprime ao desenvolvimento individual um caráter social em sua relação com a natureza e com os outros seres humanos, com o objetivo de potencializar essa atividade humana, tornando-a mais plena de prática social e de ética ambiental. Essa atividade exige sistematização através de metodologia que organize os processos de transmissão/apropriação crítica de conhecimentos, atitudes e valores políticos, sociais e históricos. Assim, se a educação é mediadora na atividade humana, articulando teoria e prática, a educação ambiental é mediadora da apropriação, pelos sujeitos, das qualidades e capacidades necessárias à ação transformadora responsável diante do ambiente em que vivem. Podemos dizer que a gênese do processo educativo ambiental é o movimento de fazer-se plenamente humano pela apropriação/transmissão crítica e transformadora da totalidade histórica e concreta da vida dos homens no ambiente (TOZONI-REIS, 2004, p. 147).

Por ser educação, a pesquisa e a ação educativa ambiental também buscam e produzem conhecimentos metodológicos. Assim, na construção de metodologias para a ação educativa ambiental algumas possibilidades pedagógicas vêm se destacando. Uma dessas possibilidades relaciona-se ao tratamento dado aos temas ambientais: qual o papel e as possibilidades metodológicas possíveis dos temas ambientais no processo educativo?

Na perspectiva da educação ambiental crítica, transformadora e emancipatória, os temas ambientais não podem ser conteúdos curriculares no sentido que a pedagogia tradicional trata os conteúdos de ensino: conhecimentos pré-estabelecidos que devem ser transmitidos de quem sabe (o educador) para quem não sabe (o educando). A educação crítica e transformadora exige um tratamento mais vivo e dinâmico dos conhecimentos, que não podem ser transmitidos de um pólo a outro do processo, mas apropriados, construídos, de forma dinâmica, coletiva, cooperativa, contínua, interdisciplinar, democrática e participativa, pois somente assim pode contribuir para o processo de conscientização dos sujeitos para uma prática social emancipatória, condição para a construção de sociedades sustentáveis. Para superar o caráter informativo em busca de uma educação preocupada com a formação do sujeito ecológico, os temas ambientais, locais - significativos, têm que ser tomados como ponto de partida para análises críticas da realidade socioambiental. Vejamos então, os temas ambientais como geradores da formação crítica como importante diretriz metodológica para a educação ambiental.

Layrargues (2001) nos ensina que os temas ambientais não podem ser 
tomados, no processo educativo ambiental, como atividades fins, mas como geradores de reflexões para a apropriação crítica dos conhecimentos sobre as relações humanas no e com o ambiente.

O estudo dos temas ambientais locais como tarefa da educação ambiental é uma recomendação da Conferência Intergovernamental sobre Educação Ambiental em Tbilisi, Geórgia - então URSS, em 1977. A Conferência de Tbilisi foi o primeiro grande evento internacional acerca da educação ambiental e até hoje é uma das principais referências dos educadores ambientais de todo mundo. A Declaração da Conferência Intergovernamental sobre Educação Ambiental de Tbilisi define como função da educação ambiental criar uma consciência e compreensão dos problemas ambientais e estimular a formação de comportamentos positivos. Os objetivos da educação ambiental são definidos como consciência, conhecimentos, comportamento, aptidões e participação. Encontramos também estruturas formais e não formais da educação ambiental considerando-a para todas as idades. As preocupações pedagógicas expressas neste documento valorizam o contato direto do educando com os elementos da natureza, os processos cognitivos de solução dos problemas ambientais, os materiais de ensino e os conteúdos e métodos interdisciplinares; a interdisciplinaridade aparece como uma prática pedagógica que tem por base as ciências naturais e sociais. Temos ainda a reorientação dos sistemas educacionais, a necessidade de divulgação dos conhecimentos e experiências ambientais positivas e a ênfase no papel dos meios de comunicação como estratégias gerais da educação ambiental. A compreensão dos problemas ambientais é um dos principais destaques do documento, que recomenda, para isto, que os temas ambientais sejam radicalmente contextualizados, isto é, que os temas ambientais mais importantes para os diferentes grupos sociais sejam aqueles que têm significado social e histórico para estes grupos, aqueles que estão presentes na vida concreta das pessoas, ou seja, os temas ambientais locais.

No entanto, para superar o tratamento conteudista, mecânico, vazio de significados concretos, entendemos que os temas ambientais locais devem ser tratados como temas geradores de reflexões mais amplas e conseqüentes para a formação crítica e transformadora dos sujeitos. Vejamos, então, mais um ponto para reflexão: o que são temas geradores? É em Paulo Freire que todos aqueles que escolhem trabalhar com a metodologia dos temas geradores têm que buscar subsídios teórico-metodológicos. 


\section{Paulo Freire}

Paulo Reglus Neves Freire nasceu no Recife, em 19 de setembro de 1921 e morreu em São Paulo, no dia 2 de maio de 1997. Viveu sua infância e juventude entre Jaboatão e Recife (de 1921 a 1964). Concluiu o curso primário em Jaboatão. Prosseguindo os estudos, formou-se em Direito, mas logo descobriu ser outra sua vocação: pelos caminhos das letras - sua primeira experiência em educação foi como professor de Português no Colégio Oswaldo Cruz, ainda no Recife (GADOTTI; FREIRE, 2001).

Minha alfabetização não me foi nada enfadonha, porque partiu de palavras e frases ligadas à minha experiência, escritas com gravetos no chão de terra do quintal. (FREIRE, 2005, p. 2)

O contato com muitos professores, artistas, intelectuais, estudantes preocupados com as condições sociais da maioria da população brasileira, nos anos 50 no Recife, foi importante para a formação do pensamento pedagógico de Paulo Freire, que viria a produzir sólidas reflexões educativas e propostas pedagógicas comprometidas com a formação crítica e a transformação social. Nas palavras de Ana Maria (FREIRE, 2001), viúva de Paulo Freire, foi como autor do Relatório da Comissão Regional de Pernambuco, intitulado “A educação de adultos e as populações marginais - o problema dos mocambos”, apresentado no II Congresso Nacional de Educação, realizado no Rio de Janeiro em julho de 1958, “que Paulo Freire firmou-se como educador progressista”. Por isso, o tema da alfabetização, compreendida de forma bastante ampliada, é tão presente em toda sua obra.

Na verdade, aquele mundo especial se dava a mim como o mundo de minha atividade perceptiva, por isso mesmo como o mundo de minhas primeiras leituras. Os “textos”, as palavras, as "letras” daquele contexto - em cuja percepção me experimentava e quanto mais fazia, mais aumentava a capacidade de perceber-se encarnavam numa série de coisas, de objetos, de sinais, cuja compreensão eu ia aprendendo no meu trato com eles, nas minhas relações com meus irmãos mais velhos e com meus 
TOZONI-REIS, M. F. de C. Temas ambientais como “temas geradores”...

\begin{abstract}
pais. Os “textos”, as palavras, as “letras” daquele contexto se encarnavam no canto dos pássaros - o do sanhaçu, o do olha-pro-caminho-quem-vem, o do bem-te-vi, o do sabiá; na dança das copas das árvores sopradas por fortes ventanias que anunciavam tempestades, trovões, relâmpagos; as águas da chuva brincando de geografia: inventando lagos, ilhas, rios, riachos, os "textos", as palavras, as "letras" daquele contexto se encarnávam também no assobio do vento, nas nuvens do céu, nas suas cores, nos seus movimentos; na cor das folhagens, na forma das folhas, no cheiro das flores das rosas, dos jasmins, no corpo das árvores, na casca dos frutos. (FREIRE, 1985, p. 13)
\end{abstract}

A experiência em Angicos-RN, realizada em três meses no início de 1963 é uma das mais conhecidas experiências de alfabetização de adultos com o "Método Paulo Freire" no Brasil (GADOtTI, 1991). Essa experiência divulgou, na época, as possibilidades pedagógicas e políticas do método, causando grande impacto, tanto nos setores progressistas da educação e da sociedade brasileira quanto nos setores mais conservadores. Paulo Freire coordenou o Programa Nacional de Alfabetização do MEC no início dos anos 60, cujo objetivo, que estava sendo competentemente construído, era alfabetizar adultos em todo o país, utilizando o Método Paulo Freire (GADOTTI, 2001). É preciso lembrar aqui que esse período foi muito rico em movimentos sociais de cultura e educação popular, e as propostas de Paulo Freire eram referência importante neste cenário, radicalmente combatidos e destruídos pelo Golpe Militar de 64, que implantou a Ditadura Militar no Brasil.

Logo após o Golpe, Paulo Freire foi preso, acusado de atividades subversivas. Ficou por 70 dias detido e depois, já em liberdade, mas muito perseguido, partiu para o exílio, que se estendeu de setembro de 1964 a junho de 1980 . Passou pela Bolívia rapidamente e, contratado como assessor de educação primária e de adultos, viveu em Santiago, no Chile, como assessor de Jacques Chonchol, Presidente do Institututo de Desarrollo Agropecuario (Indap) e mais tarde como consultor da Unesco. No Chile, escreveu muitos livros importantes para o conjunto de sua obra. Morou algum tempo nos Estados Unidos, mas foi em Genebra, no Conselho Mundial das Igrejas, que viveu de forma mais estável (GADOTTI, 1991, 2001). Como professor na Universidade de Genebra desenvolveu experiências na Ásia, Oceania, América e, principalmente na África de língua portuguesa, nos países de Cabo Verde, Angola, São Tomé e Príncipe, Guiné-Bissau (freIRE, 1985). A partir de Genebra, Paulo Freire projetou-se na história da educação no século XX como um cidadão do mundo: amadureceu muito na vivência em diferentes culturas. Com a anistia, dezessete anos após 
partir para o exílio, Paulo Freire retornou definitivamente ao Brasil.

Voltou para viver em São Paulo como Professor da PUC-SP e mais tarde da Unicamp. Em 1998, viúvo de Elza, casou-se com Ana Maria Araújo. De 1989 a maio de 1991 Paulo Freire ocupou o cargo de Secretário da Educação da Cidade de São Paulo na gestão da Prefeita Luiza Erundina (GADOTTI, 1991; GADOTTI \& FREIRE, 2001). No campo da educação ambiental foram tão inspiradoras suas idéias acerca da educação dos sujeitos no mundo, que fizeram com que, em 1992, ele fosse escolhido como representante da educação ambiental na ECO-92 e grande referência na elaboração do Tratado de Educação Ambiental para Sociedades Sustentáveis e Responsabilidade Global do Fórum das ONGs.

Paulo Freire não se dedicou especificamente ao estudo da educação ambiental, mas sua leitura de mundo sistematizada, tendo sido tão ampla quanto profunda, abre possibilidades para refletirmos sobre essa compreensão de educação subsidiada em sua teoria do conhecimento. Paulo nos ensinou não só o processo de como se pode conhecer, mas, sobretudo, através de sua práxis teórica, nos oferece meios para refletirmos sobre o ético, o político e o pedagógico no ato de ensinar-aprender. Por isso, inúmeros cientistas das mais diversas áreas do conhecimento têm se valido de seu pensamento para criar novos saberes. Podemos, pois, procurar na sua obra e práxis os pressupostos teóricos para subsidiar a educação ambiental que nos demanda mais do que qualquer outra ao cuidado, ao entendimento e à preservação da VIDA. Procurar não mecanicamente porque outros e outras fizeram-no e continuam fazendo na busca de construir corpos teóricos dentro das ciências às quais se dedicam, mas, porque, na verdade, sua teoria é capaz disso. Ela, estou certa, tem muito a dizer e a propor para a ação dos que se preocupam séria, intencionalmente e sistematicamente com a necessária educação ambiental vista na sua totalidade. (FREIRE, 2003, p. 11)

Suas principais obras são Educação como prática da liberdade (1967); Pedagogia do oprimido (1970); Conscientização (1980); Pedagogia da esperança (1992); Cartas a Cristina (1994); À sombra desta mangueira (1995); Pedagogia da autonomia (1997); Pedagogia da indignação (2000), textos reunidos que Ana Maria publicou (GADOTTI; FREIRE, 2001). 


\section{A metodologia do tema gerador}

Os temas geradores são, no Método Paulo Freire, o eixo da proposta metodológica. Entendemos que o Método é o próprio pensamento de Paulo Freire, é o conjunto de fundamentos filosófico-políticos presentes na sua teoria do conhecimento, conhecimento e ação no mundo, a educação libertadora. A idéia mais geral da educação libertadora é que a educação é uma atividade em que os sujeitos, educadores e educandos, mediatizados pelo mundo educam-se em comunhão. A esse processo, Paulo Freire chamou de processo de conscientização, isto é, ao se aprofundarem no conhecimento da realidade, realidade vivida, real e concretamente pelos sujeitos, os educandos têm as possibilidades de emergir no conhecimento de sua própria condição, de sua própria vida. A educação libertadora é, para esse educador, a alternativa política à educação tradicional, a que ele denominou “educação bancária”, a que, por opção política e metodológica de caráter domesticador, realiza-se por repassar conhecimentos de educadores para educandos. Assim, a educação libertadora tem, como pressuposto, o questionamento radical das relações dos homens entre si e deles com o mundo em que vivem, criando oportunidades para um processo de desvelamento do mundo tendo como objetivo último a transformação social, entendendo que a educação não é a garantia das transformações sociais, mas que as transformações são impossíveis sem ela, sem uma visão crítica da realidade (FREIRE, 1967, 1984).

Na pedagogia Paulo Freire vemos que educar é um ato de conhecimento da realidade concreta, das situações vividas, um processo de aproximação crítica da própria realidade: compreender, refletir, criticar e agir são as ações pedagógicas pretendidas. A construção teórica da pedagogia da libertação era a atividade que mais interessava a Paulo Freire, porém, os resultados das primeiras experiências práticas com a alfabetização de adultos obrigava-o a trabalhar mais sobre questões didático-metodológicas (GADOTTI, 2001). A substituição da formação convencional das salas de aula pela formação em círculos e as técnicas de trabalho em grupo como as discussões, o grupo de estudo, o grupo de ação, o fórum, o grupo de debate e a carta temário, todas essas alternativas à exposição didática, foram pensadas para criar o “clima do debate”, elemento central do processo de descoberta do conhecimento. Partir do conhecimento, dos saberes existentes, mesmo que não percebidos como saberes, é o caminho metodológico pretendido. Esse processo é o processo de conscientização, isto é, discutir os conteúdos da "consciência ingênua” do mundo e das coisas em busca da "consciência crítica” é o significado da educação. As técnicas de 
ensino são possibilidades metodológicas de problematização do mundo, das idéias e das coisas, são formas metodológicas de promover o questionamento, pois o que se pretende é a leitura crítica do mundo.

Paulo Freire acreditava que "a leitura do mundo precede sempre a leitura da palavra e a leitura desta implica sempre a continuidade da leitura daquele" (FREIRE, 1985), precede no sentido de vir antes, mas também, e principalmente, no sentido de ser mais importante: "o movimento do mundo à palavra e da palavra ao mundo está sempre presente” (FREIRE, 1985). Ele acreditava que não tem nenhum sentido os educandos aprenderem a decodificar as sílabas de uma palavra sem compreender seu sentido, social e político. Portanto, era preciso criar um "universo vocabular" com que fossem geradores de discussão sobre a realidade vivida.

No processo de criação do "método", Paulo Freire, do mesmo modo como ocorrera com sua própria alfabetização, destaca o universo vocabular do alfabetizando como ponto de partida: conhecer o contexto dos educandos, que vão aprender a ler, para descobrir, pela pesquisa, o universo da linguagem para retirar, da vida cotidiana, o vocabulário a ser utilizado no processo de alfabetização (GADOTTI, 1998). Portanto, não é qualquer palavra que pode se tornar uma "palavra problematizadora", porque a problematização aqui não é uma atividade de exercício intelectual vazio de significado político, ao contrário, para o Método, a palavra problematizadora não é um exercício de linguagem, mas uma discussão conscientizadora da realidade vivida, da realidade opressora das sociedades desiguais. $\mathrm{O}$ interesse por aprender a ler a palavra escrita deve ter como ponto de partida e também como ponto de chegada a problematização das situações reais através do diálogo para a compreensão das situações-problema.

O método de alfabetização de adultos que emergiu do pensamento Paulo Freire tomou as "palavras geradoras" como metodologia, conferindo-lhe o papel de "tema gerador" (FREIRE, 1985). Temos, então, que o tema gerador é o tema ponto de partida para o processo de construção da descoberta. Por emergirem do saber popular, os temas geradores são extraídos da prática de vida dos educandos, substituem os conteúdos tradicionais e são buscados através da "pesquisa do universo vocabular". É importante destacar que o caráter político da pedagogia freireana faz-se presente, de forma radical, nos temas geradores; isto é, temas geradores só são geradores de ação-reflexão-ação se forem carregados de conteúdos sociais e políticos com significado concreto para a vida dos educandos. 
TOZONI-REIS, M. F. de C. Temas ambientais como “temas geradores”...

\begin{abstract}
A palavra tijolo, por exemplo, se inseriria numa representação pictória, a de um grupo de pedreiros, por exemplo, construindo uma casa. Mas, antes da devolução, em forma escrita, da palavra oral dos grupos populares, a eles, para o processo de sua apreensão e não de sua memorização mecânica, costumávamos desafiar os alfabetizandos com um conjunto de situações codificadas de cuja decodificação ou "leitura” resultava a percepção crítica do que é cultura, pela compreensão da prática ou do trabalho humano, transformador do mundo. No fundo, esse conjunto de representações de situações concretas possibilitava aos grupos populares uma "leitura” da "leitura” anterior do mundo, antes da leitura da palavra. (FREIRE, 1985, p. 23)
\end{abstract}

Então, os temas geradores são temas que servem ao processo de codificação-decodificação e problematização da situação. Eles permitem concretizar, metodologicamente, o esforço de compreensão da realidade vivida para alcançar um nível mais crítico de conhecimento dessa realidade, pela experiência da reflexão coletiva da prática social real. Esse é o caminho metodológico: o trabalho educativo dispensa, pois, um programa pronto e as atividades tradicionais de escrita e leitura, mecanicamente executadas. A avaliação é um processo coletivo cujo foco não é o "rendimento" individual, mas o próprio processo de conscientização. O diálogo é, portanto, o método básico, realizado pelos temas geradores de forma radicalmente democrática e participativa.

Para a pedagogia libertadora, a forma de trabalho educativo é o grupo de discussão, que conduz o processo educativo buscando os conteúdos problematizadores, realizando as discussões, compartilhando as descobertas, definindo as atividades e os temas geradores como ponto de partida para a decodificação das sílabas e, principalmente, a decodificação do mundo social, histórico, político e cultural onde vivem os oprimidos nas sociedades desiguais.

\title{
Os temas ambientais como temas geradores
}

Um dos princípios metodológicos mais conhecidos da educação crítica e transformadora, muito anunciado nas propostas de educação ambiental, é a idéia da educação como um processo de conscientização. De tão presente nas diferentes propostas educativas ambientais, a conscientização chega a ser, de 
certa forma, banalizada, ou seja, quase todas as propostas educativas ambientais anunciam como objetivo a conscientização, embora tenham princípios, estratégias e práticas bastante diferenciadas e, algumas vezes, muito distantes dos conteúdos filosófico-políticos que a explicam.

O termo conscientização é carregado destes conteúdos filosófico-políticos. Paulo Freire foi, sem dúvida, o principal responsável pela incorporação deste termo ao discurso dos educadores. Vejamos como ele o descobriu:

ao ouvir pela primeira vez a palavra conscientização, percebi imediatamente a profundidade de seu significado, porque estou absolutamente convencido de que a educação, como prática de liberdade, é um ato de conhecimento, uma aproximação crítica da realidade. (FREIRE, 1980, p. 25)

Este termo, expressão do processo educativo buscado pela pedagogia libertadora de Paulo Freire, parte da constatação de que é fundamental neste processo a necessidade de superação do conhecimento imediato da realidade em busca de sua compreensão mais elaborada, mais refletida. Desta forma, o processo de conscientização tem no ato ação-reflexão-ação a unidade dialética que o define:

Num primeiro momento a realidade não se dá aos homens como objeto cognoscível por sua consciência crítica. Noutros termos, na aproximação espontânea que o homem faz do mundo, a posição normal fundamental não é uma posição crítica, mas uma posição ingênua. A este nível espontâneo, o homem ao aproximar-se da realidade faz simplesmente a experiência da realidade na qual está e procura. Essa tomada de consciência não é ainda a conscientização porque esta consiste no desenvolvimento crítico da tomada de consciência. A conscientização implica, pois, que ultrapassemos a esfera espontânea de apreensão da realidade, para chegarmos a uma esfera crítica na qual a realidade se dá como objeto cognoscível e na qual o homem assume uma posição epistemológica. (FREIRE, 1980, p. 26)

Assim, o processo de conscientização, pela educação (ação-reflexão- 
ação), é a possibilidade de superação da consciência ingênua em busca da consciência crítica, dois "graus" de consciência que para Paulo Freire expressam o movimento de emersão da consciência das condições criadas pela sociedade opressora. Enquanto a consciência ingênua é simplista, superficial, saudosista, massificadora, mística, passional, estática, imutável, preconceituosa e sem argumentos, a consciência crítica não se satisfaz com aparências, reconhece que a realidade é mutável, substitui explicações mágicas por princípios autênticos de causalidade, está sempre disposta a revisões, repele preconceitos, é inquieta, autêntica, democrática, indagadora, investigadora e dialógica (FREIRE, 1984).

Assim, conscientização é um processo de ação concreta e reflexão histórica que implica opções políticas e articula conhecimentos e valores para a transformação das relações sociais. Ao incorporar o tema ambiental, o processo da educação conscientizadora tem como objetivo a transformação das relações entre os sujeitos e desses com o ambiente, estabelecidas pela história das relações sociais. A educação ambiental como mediadora dessas relações se estabelece sobre a idéia de conscientização, na articulação entre conhecimentos, valores, atitudes e comportamentos, se puder promover a transformação radical da sociedade de hoje rumo à sustentabilidade, também radical, que implica transformar a relação dos sujeitos com o ambiente, compreendendo-o social e histórico. Conscientização é, portanto, um processo de construção, ativa e refletida dos sujeitos, rumo à consciência crítica, assim, supera a apropriação de conhecimentos, referindo-se a articulação radical entre conhecimento e ação, não qualquer ação, mas uma ação política, transformadora, libertadora e emancipatória. Esse processo é histórico e concreto, não imediato. Conscientização, como princípio da educação ambiental, não é um resultado imediato da aquisição de conhecimentos sobre os processos naturais, mas a reflexão filosófica e política, carregada de escolhas históricas que resultam na busca de uma sociedade sustentável.

A educação em busca da tematização do ambiente que se pretenda crítica, transformadora e emancipatória tem na educação libertadora referência e inspiração. Além de identidade filosófico-política, busquemos também inspiração didático-pedagógica nestas referências. O processo de conscientização como princípio metodológico traz a possibilidade de construção da metodologia do tema gerador como um importante recurso para a educação ambiental por seu potencial reflexivo e problematizador.

Assim, as propostas educativas ambientais conscientizadoras podem tomar os temas ambientais locais como temas geradores desta ação conscientizadora, desde que estes temas sejam carregados de conteúdos socioambientais 
significativos para os educandos e sejam definidos coletiva e participativamente. Vimos neste texto como Layrargues (2001), a partir da proposta de Tbilisi para a educação ambiental no que diz respeito à resolução de problemas ambientais locais conclui que, se articulada às propostas de participação social, engajamento, mobilização e emancipação, a resolução dos problemas locais deve ser um tema gerador e não uma atividade-fim nos projetos de educação ambiental. Esse mesmo autor, num outro momento (LAYRARGUES, 2002), discute os equívocos cometidos no uso da reciclagem do lixo como temática da educação ambiental, concluindo que enquanto a educação ambiental não problematizar criticamente seus temas não poderá ser considerada educação transformadora, educação conscientizadora.

\begin{abstract}
A resolução dos problemas ambientais locais carrega um valor altamente positivo, pois foge da tendência desmobilizadora da percepção dos problemas globais, distantes da realidade local, e parte do princípio de que é indispensável que o cidadão participe da organização e gestão do seu ambiente de vida cotidiano. Aqui, a participação transcende a clássica fórmula de mera consulta à população, pois molda uma nova configuração da relação Estado e sociedade, já que envolve também o processo decisório. Participação, engajamento, mobilização, emancipação e democratização são as palavras-chave. O Contexto local é uma ferramenta da educação ambiental que permite o desenvolvimento da qualidade dinâmica nos educandos, despertando o sentimento da visão crítica e da responsabilidade social, vitais para a formação da cidadania. Porém, a estratégia da resolução dos problemas ambientais locais como metodologia da educação ambiental permite que dois tipos de abordagens possam ser realizadas: ela pode ser considerada tanto como um tema-gerador de onde se irradia uma concepção pedagógica comprometida com a compreensão e transformação da realidade; ou como uma atividade-fim, que visa unicamente a resolução pontual daquele problema ambiental abordado. (LAYRARGUES, 2001, p. 134).
\end{abstract}

Loureiro (2004, p. 133) defende também a problematização dos temas ambientais como proposta pedagógica para a educação ambiental quando afirma:

Por outro lado, por mais que se admita a relevância pedagógica como 
TOZONI-REIS, M. F. de C. Temas ambientais como “temas geradores”...

\begin{abstract}
etapa inicial do educar, não cabe ficar no plano da sensibilização, do reconhecimento do ambiente de vida, da ação no universo particular e de alterações de comportamentos individuais, como coisas válidas em si e suficientes para transformações societárias. É preciso articular a cotidianidade ao macrossocial, em uma atuação política que gere as transformações individuais e coletivas, simultaneamente, e a possibilidade de as experiências localizadas que foram bem-sucedidas se universalizarem.
\end{abstract}

A educação ambiental para a sustentabilidade, capaz de atuar na formação de sujeitos sociais críticos, participativos, que se pautem pela construção de uma sociedade em que a sustentabilidade seja entendida também como democracia, equidade, justiça, autonomia e emancipação, é nossa referencia neste estudo. Isso significa superar a idéia, muito presente nas propostas de educação ambiental, de que a educação ambiental tem como objetivo a "mudança de comportamento" dos sujeitos em busca de comportamentos considerados ambientalmente corretos, configurando-se, como nos ensina Brügger (1994) num adestramento ambiental. Neste sentido, temos também que buscar a superação do caráter moralista e moralizante que temos observado em algumas ações educativas ambientais (LOUREIRO, 2004) para a construção da educação ambiental crítica e emancipatória. Esse autor chama nossa atenção para a necessidade de superação das propostas educativas ambientais ingênuas e descomprometidas, social e politicamente, em busca de atividades mais consistentes e conseqüentes comprometidas com a construção de sociedades mais justas e igualitárias.

Ao tomar os temas ambientais como temas geradores de processos educativos ambientais duas preocupações devem estar presentes: os temas têm que ter significado concreto para os envolvidos e devem ter conteúdo problematizador. Isso significa dizer que os temas ambientais devem ser ponto de partida para a discussão mais ampla da crise do modelo civilizatório que estamos a enfrentar, crise que dá sentido à busca de uma sociedade sustentável. Assim, os temas mais comumente tratados nas propostas educativas ambientais como recursos hídricos, resíduos sólidos, desmatamento, queimadas, mata ciliar, extinção das espécies animais, etc., só têm perspectiva educativa plena se abandonarmos o caráter conteudista da pedagogia tradicional - que trata os conteúdos com objetivos em si mesmos - e dermos um tratamento problematizador a eles, isto é, se, a partir do processamento das informações sobre estes temas, educadores e educandos, coletiva e participativamente, buscarem empreender 
reflexões acerca dos conflitos que emergem dos condicionantes históricos, políticos, sociais e culturais dos problemas e soluções ambientais. Tratar os temas ambientais como temas geradores do processo de ação-reflexão-ação é construir uma base metodológica para a educação ambiental que tenha como perspectiva os objetivos da educação ambiental expressos no Tratado para a Educação Ambiental e Responsabilidade Global:

contribuir para a construção de sociedades sustentáveis e eqüitativas ou socialmente justas e ecologicamente equilibradas e gerar, com urgência, mudanças na qualidade de vida e maior consciência de conduta pessoal, assim como harmonia entre os seres humanos e destes com outras formas de vida (FÓRUM INTERNACIONAL DAS ONGs, 1995).

\section{REFERÊNCIAS}

BRÜGGER, P. Educação ou adestramento ambiental? Florianópolis: Letras Contemporâneas, 1994.

FORUM INTERNACIONAL DAS ONGs. Tratado de educação ambiental para sociedades sustentáveis e responsabilidade global. Rio de Janeiro, 1995.

FREIRE, A. M. A. A voz da esposa: a trajetória de Paulo Freire. Instituto Paulo Freire. Disponível em: http.www.paulofreire.org. Acesso em: 15 nov. 2005.

. O legado de Paulo Freire à educação ambiental. In: NOAL, F. O.; BARCELOS, V. H. L. Educação ambiental e cidadania: cenários brasileiros. Santa Cruz do Sul, RS: Edunisc, 2003.

. Pedagogia da libertação em Paulo Freire. São Paulo: Edunesp, 2001.

FREIRE, P. A educação como prática de liberdade. Rio de Janeiro: Paz e Terra, 1967.

. A importância do ato de ler. São Paulo: Cortez/Autores Associados, 1985.

. Conscientização. São Paulo: Moraes, 1980.

. Depoimento. Coleção Grandes Educadores: Paulo Freire. Produzido e distribuído por ATTA Mídia e Educação, s.d. 1 VHS.

Pedagogia do oprimido. Rio de Janeiro: Paz e Terra, 1984. 
TOZONI-REIS, M. F. de C. Temas ambientais como "temas geradores"...

GADOTTI, M. Convite à leitura de Paulo Freire. São Paulo: Scipione, 1991.

. História das idéias pedagógicas. São Paulo: Ática, 2001.

. Pedagogia da práxis. São Paulo: Cortez/Instituto Paulo Freire, 1998.

GADOTTI, M.; FREIRE, A. M. A. Paulo Freire: uma biobibliografia. São Paulo: Cortez/Instituto Paulo Freire/Unesco, 2001.

GADOTTI, M.; FREIRE, P.; GUIMARÃES, S. Pedagogia: diálogo e conflito. Cortez/Autores Associados, 1995.

LAYRARGUES, P. P. A resolução de problemas ambientais locais deve ser um tema gerador ou a atividade-fim da educação ambiental? In: REIGOTA, M. (Org.). Verde cotidiano: o meio ambiente em discussão. Rio de Janeiro: DP\&A, 2001.

. O cinismo da reciclagem: o significado ideológico da reciclagem de lata de alumínio e suas implicações para a educação ambiental. In: LOUREIRO, C. F. B.; LAYRARGUES, P. P.; CASTRO, R. S. Educação ambiental: repensando o espaço da cidadania. São Paulo: Cortez, 2002.

LOUREIRO, C. F. B. Trajetórias e fundamentos da educação ambiental. São Paulo: Cortez, 2004.

TOZONI-REIS, M. F. C. Educação ambiental: natureza, razão e história. Campinas: Autores Associados, 2004.

Texto recebido em 04 set. 2005

Texto aprovado em 08 out. 2005 